\title{
Coligand Effects on the Field-Induced Double Slow Magnetic Relaxation in Six-Coordinate Cobalt(II) Single-Ion Magnets (SIMs) with Positive Magnetic Anisotropy $\uparrow$
}

Julia Vallejo, ${ }^{\dagger}$ Marta Viciano-Chumillas,${ }^{\dagger}$ Francisco Lloret, ${ }^{\dagger}$ Miguel Julve,${ }^{\dagger}$ Isabel Castro, ${ }^{\dagger} \mathrm{J}$. Krzystek, ${ }^{*}{ }^{\ddagger}$ Mykhaylo Ozerov,${ }^{\ddagger}$ Donatella Armentano, ${ }^{\S}$ Giovanni De Munno, ${ }^{*,}$ and Joan $\mathrm{Cano}^{*, \dagger}$

${ }^{\dagger}$ Institut de Ciència Molecular (ICMol) and Departament de Química Inorgànica, Universitat de València, 46980 Paterna, València.E-mail:joan.cano@uv.es

${ }^{\ddagger}$ National High Magnetic Field Laboratory (NHMFL), Florida State University, Tallahassee, Florida 32310, United States. E-mail: krzystek@magnet.fsu.edu

${ }^{\S}$ Dipartamento di Chimica e Tecnologie Chimiche, Università della Calabria, 87036 Rende, Cosenza, Italy. E-mail: giovanni.demunno@unical.it

\section{List of Contents}

Figure S1. The powder XRPD pattern of 1.

Figure S2. The powder XRPD pattern of 2.

Figure S3. IR spectrum $\left(400-4000 \mathrm{~cm}^{-1}\right)$ of 1 .

Figure S4. IR spectrum $\left(400-4000 \mathrm{~cm}^{-1}\right)$ of 2 .

Figure S5. HFEPR spectra of solid polycrystalline samples of $\mathbf{1}$ and $\mathbf{2}$.

Figure S6. Field vs. frequency map of turning points in the HFEPR spectra for $\mathbf{1}$ and $\mathbf{2}$ at 4.5 $\mathrm{K}$.

Figure S7. HFEPR spectrum of 1 at $208 \mathrm{GHz}$.

Figure S8. Temperature dependence of $\chi_{M}^{\prime}$ (left) and $\chi_{M}^{\prime \prime}$ (right) of 1 in applied dc fields of 0.5 (a) and 2.5 (b) $\mathrm{kG}$ and under $\pm 5.0 \mathrm{G}$ oscillating field at frequencies in the range of 0.6 (black) to 10.0 (green) $\mathrm{kHz}$. The filled circles and solid lines are experimental data and simulated curves, respectively.

Figure S9. Temperature dependence of $\chi_{M}^{\prime}$ (left) and $\chi^{\prime \prime}$ (right) of 2 in applied dc fields of 0.5 (a) and 2.5 (b) $\mathrm{kG}$ and under $\pm 5.0 \mathrm{G}$ oscillating field at frequencies in the range of 0.6 (black) to 10.0 (green) $\mathrm{kHz}$. The filled circles and solid lines are experimental data and simulated curves, respectively. 
Figure S10. Cole-Cole plots at 5.0 K (blue dots), 5.5 K (red dots), $6.0 \mathrm{~K}$ (green dots) and 6.5 $\mathrm{K}$ (purple dots) for 1 (a) and 2 (b) under applied dc fields of 0.5 (left) and $2.5 \mathrm{kG}$ (right). Solid lines represent the best fit (see text).

Figure S11. Arrhenius plots for 1 (a) and 2 (b) under applied dc fields of 0.5 (left) and $2.5 \mathrm{kG}$ (right). Solid lines represent the best fit (see text) through the models described in eqs (4) [Orbach + Orbach, in black] and (6) [Raman, in grey]. Error bars do not appear because they are smaller than the dots used to visualize the experimental data (standard deviation in $1 / T$ less than 0.002).

Figure S12. Frequency dependence of $\chi^{\prime \prime} \mathrm{M}$ of 1 (left) and 2 (right) in applied dc fields of 0.5 (a) $1.0 \mathrm{kG}$ (b), and 2.5 (c) $\mathrm{kG}$ and under $\pm 5.0 \mathrm{G}$ oscillating field at temperatures in the range from 3.5 (orange) to $6.5 \mathrm{~K}$ (blue) in steps of $0.25 \mathrm{~K}$. The filled circles and solid lines are experimental data and simulated curves, respectively.

Figure S13. Arrhenius plots for 1 (left) and 2 (right) under applied dc fields of 0.5 (a), 1.0 (b), and $2.5 \mathrm{kG}$ (c). Solid lines represent the best fit (see text) through the models described in eqs (4) [Orbach + Orbach, in black] and (6) [Raman, in grey]. Error bars do not appear because they are smaller than the dots used to visualize the experimental data (standard deviation in $\ln (\tau)$ less than 0.007).

Table S1. Intermolecular $\pi \cdots \pi$ interactions in $\mathbf{1}$ (distances in $\AA$ and angles in deg)

Table S2. Energy of the calculated quartet $\left(\mathrm{Q}_{\mathrm{i}}\right)$ and triplet $\left(\mathrm{D}_{\mathrm{i}}\right)$ excited states and their contributions to the $D$ and $E$ values for 1 obtained from CASSCF/NEVPT2 calculations. $D_{\mathrm{SS}}$ is the spin-spin contribution to axial $z f s$ parameter, and $D_{\mathrm{Q}}$ and $D_{\mathrm{D}}$ are the sum of spin-orbit contributions coming from quartet and doublet excited states

Table S3. Energy of the calculated quartet $\left(\mathrm{Q}_{\mathrm{i}}\right)$ and triplet $\left(\mathrm{D}_{\mathrm{i}}\right)$ excited states and their contributions to the $D$ and $E$ values for 2 obtained from CASSCF/NEVPT2 calculations. $D_{\mathrm{SS}}$ is the spin-spin contribution to axial $z f s$ parameter, and $D_{\mathrm{Q}}$ and $D_{\mathrm{D}}$ are the sum of spin-orbit contributions coming from quartet and doublet excited states

Table S4. Selected ac magnetic data for $\mathbf{1}$ and $\mathbf{2}$ at different dc applied fields

Table S5. Selected results obtained from the analysis of the ac magnetic data for $\mathbf{1}$ at different dc applied fields using different combinations of the relaxation mechanisms

Table S6. A comparison between a selection of theoretical and experimental vibrational frequencies for $\mathbf{1}$ and $\mathbf{2}$

Table S7. Selected ac magnetic data for $\mathbf{1}$ and $\mathbf{2}$ at different dc applied fields extracted from the frequency dependence of $\chi^{\prime \prime} \mathrm{M}$ 


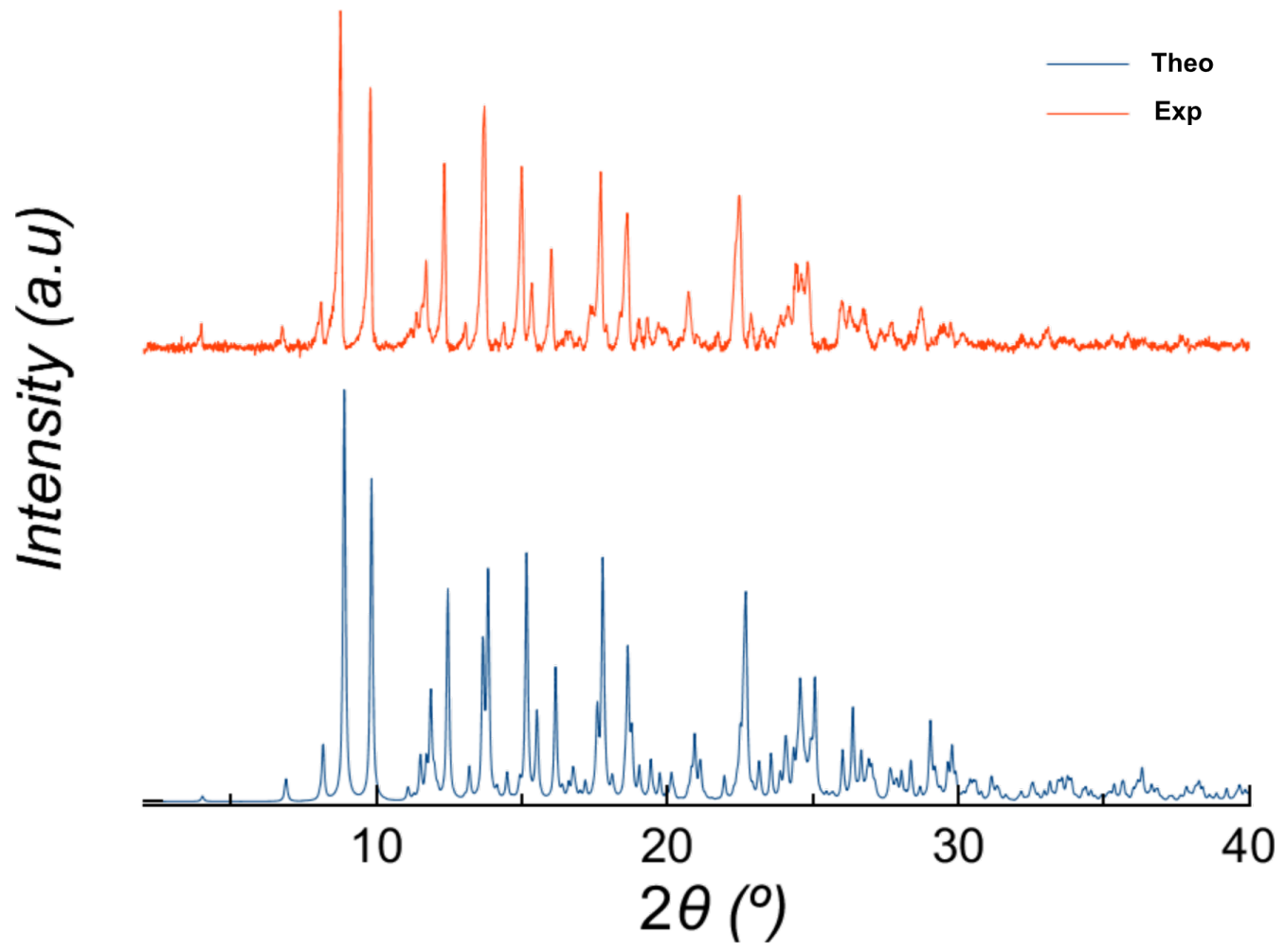

Figure S1. The powder XRPD pattern of $\mathbf{1}$.

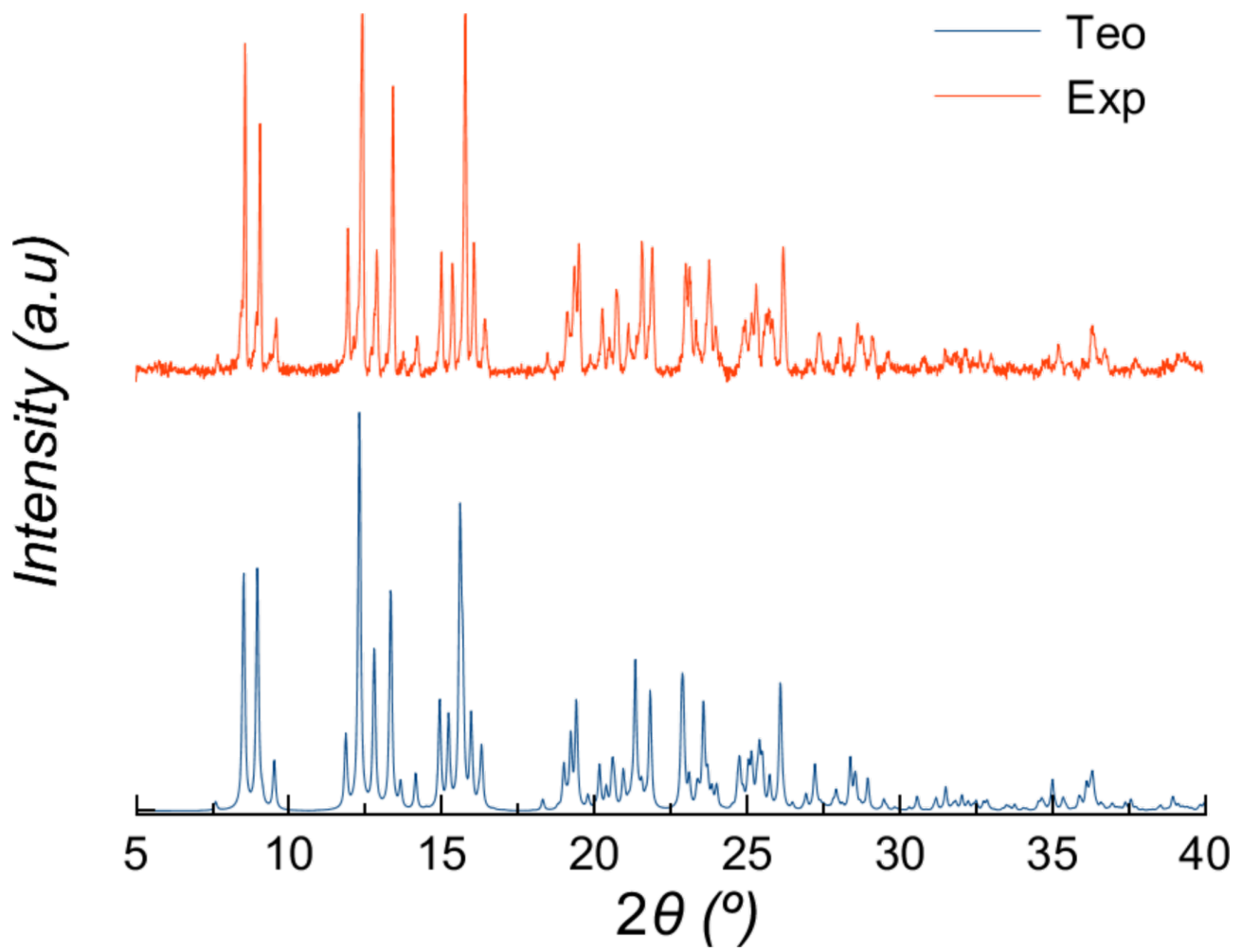

Figure S2. The powder XRPD pattern of 2 . 


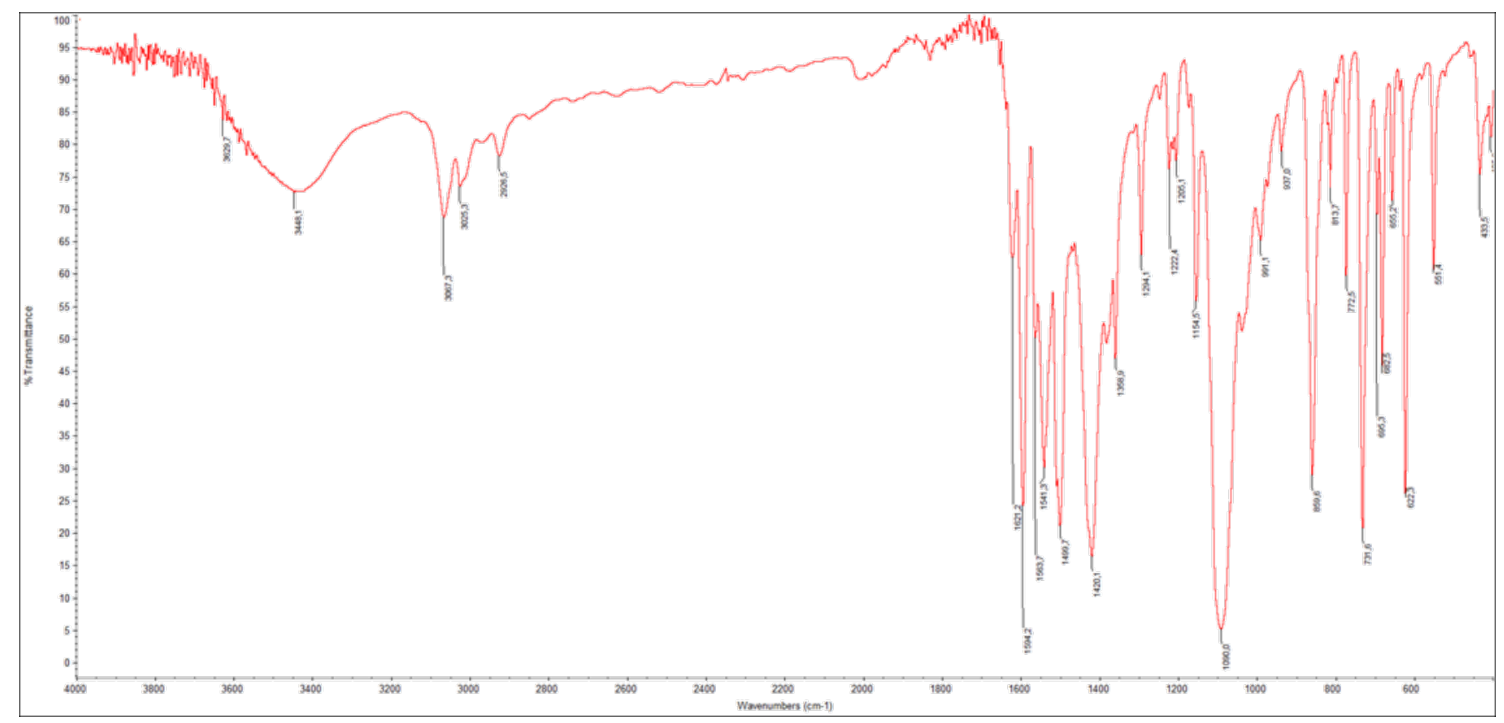

Figure S3. IR spectrum $\left(400-4000 \mathrm{~cm}^{-1}\right)$ of 1 .

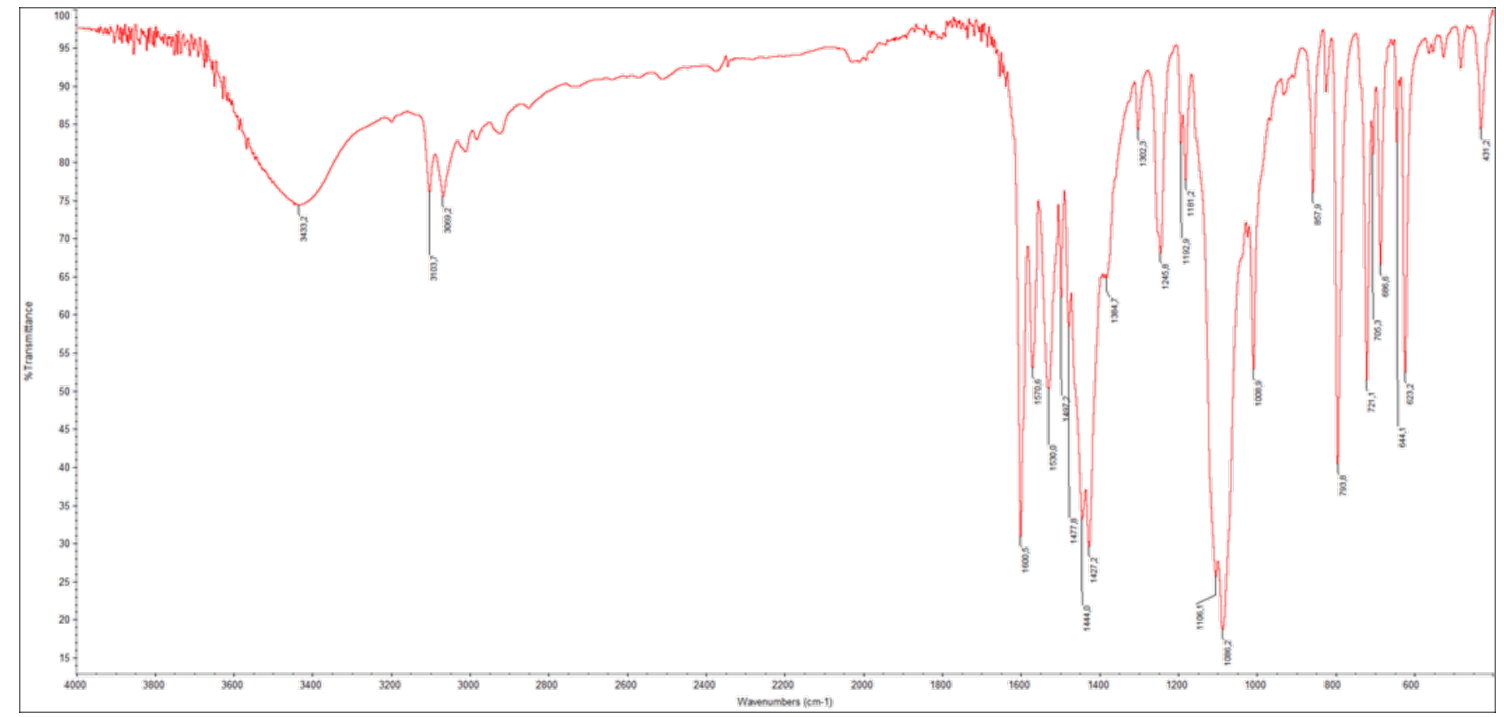

Figure S4. IR spectrum $\left(400-4000 \mathrm{~cm}^{-1}\right)$ of 2 . 


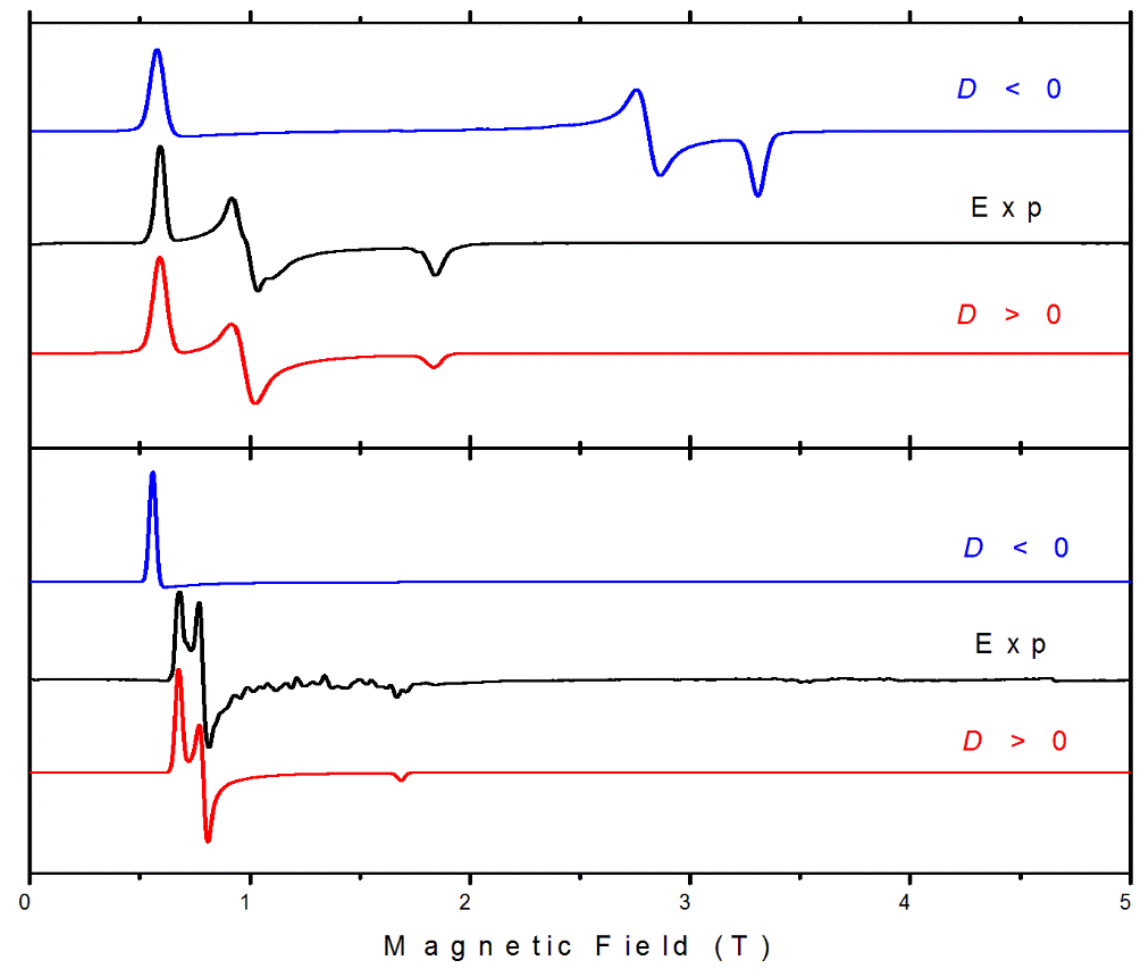

Figure S5. HFEPR spectra of solid polycrystalline samples of $\mathbf{1}$ (top) and $\mathbf{2}$ (bottom) at $4.5 \mathrm{~K}$ and $52 \mathrm{GHz}$. Solid blue and red lines represent simulations with negative and positive $D$ values, respectively, with $|D|$ assumed as 58 and $64 \mathrm{~cm}^{-1}$, respectively. The other spin Hamiltonian parameters are: $S=3 / 2, E / D=0.167, g_{\perp}=2.57, g_{\|}=2.195$ for 1 and $S=3 / 2, E / D=0.052, g_{\perp}=$ $2.55, g_{\|}=2.28$ for $\mathbf{2}$, obtained from 2-D maps of resonances (field $v s$. frequency, Fig. S6) along the tunable-frequency EPR methodology. ${ }^{83}$ 

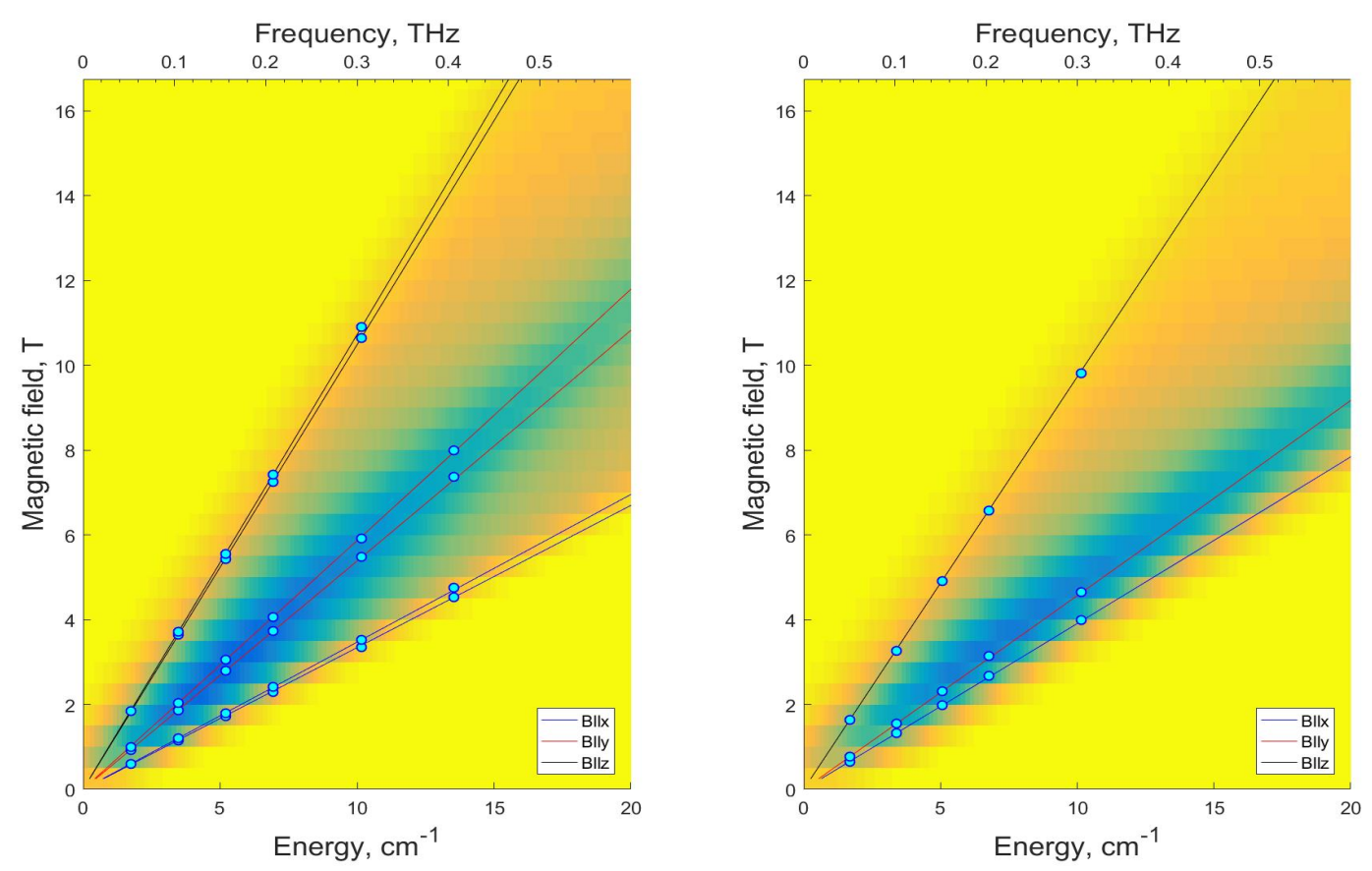

Figure S6. Field $v s$. energy or frequency map of turning points in the HFEPR spectra for 1 (left) and 2 (right) at $4.5 \mathrm{~K}$. The circles are experimental points; lines represent turning points and were drawn using best-fitted parameters as in Table 3. Both the circles and lines were superimposed on simulated false-color (contour) maps showing the absorption intensity at the given point of the 2D map, analogously to the FIRMS presentations in the main text Fig. 5).

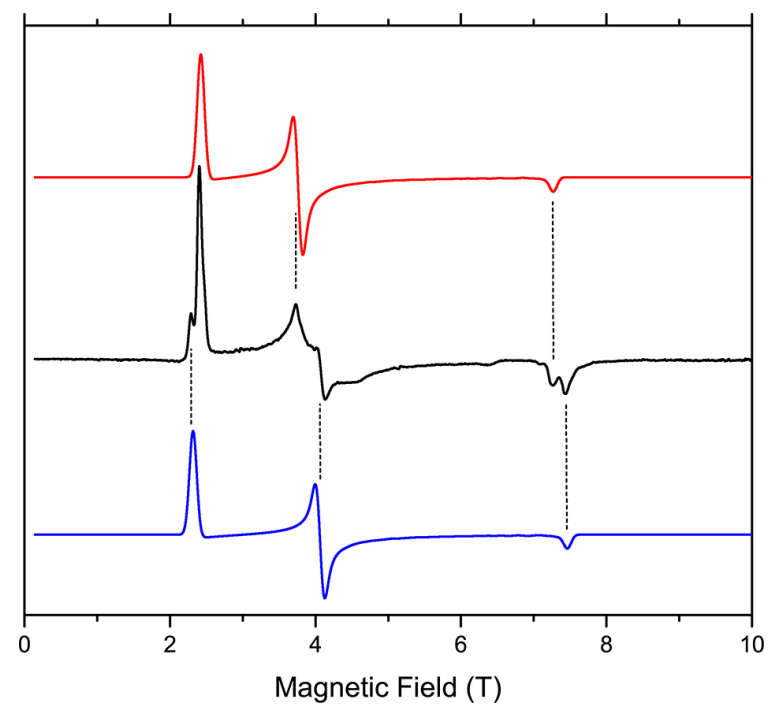

Figure S7. HFEPR spectrum of 1 at $208 \mathrm{GHz}$ (black trace) together with simulations using two different sets of spin Hamiltonian parameters as in Table 3. Red trace: Co1 (smaller rhombicity); blue trace: Co2 (larger rhombicity). The dashed lines are eye-guides to indicate the particular species. The attribution of the turning points to a particular site is arbitrary, but was suggested by the CASSCF calculations. 

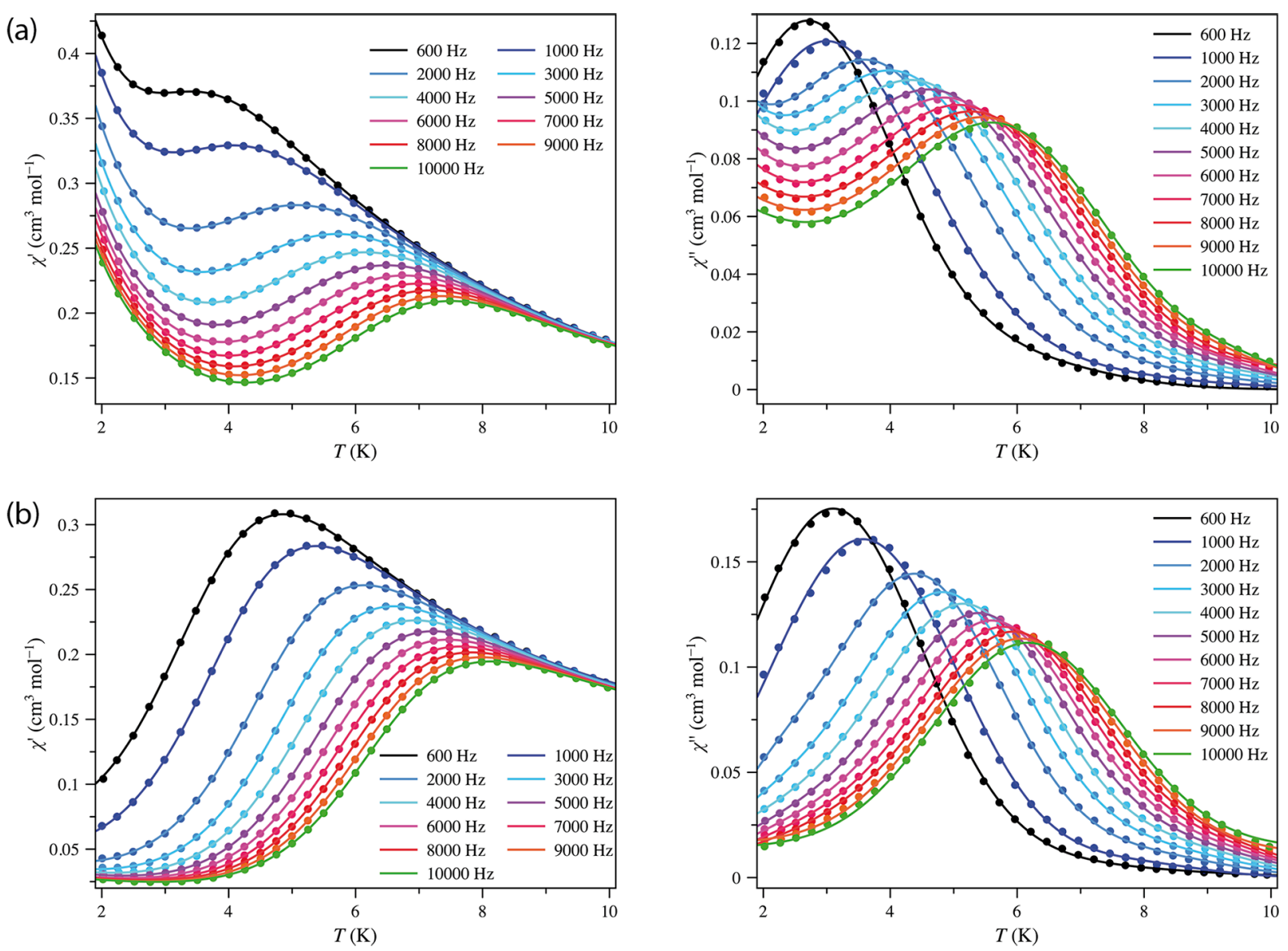

Figure S8. Temperature dependence of $\chi_{M}^{\prime}$ (left) and $\chi^{\prime \prime}$ (right) of 1 in applied dc fields of 0.5 (a) and 2.5 (b) $\mathrm{kG}$ and under $\pm 5.0 \mathrm{G}$ oscillating field at frequencies in the range of 0.6 (black) to 10.0 (green) $\mathrm{kHz}$. The filled circles and solid lines are experimental data and simulated curves, respectively. 

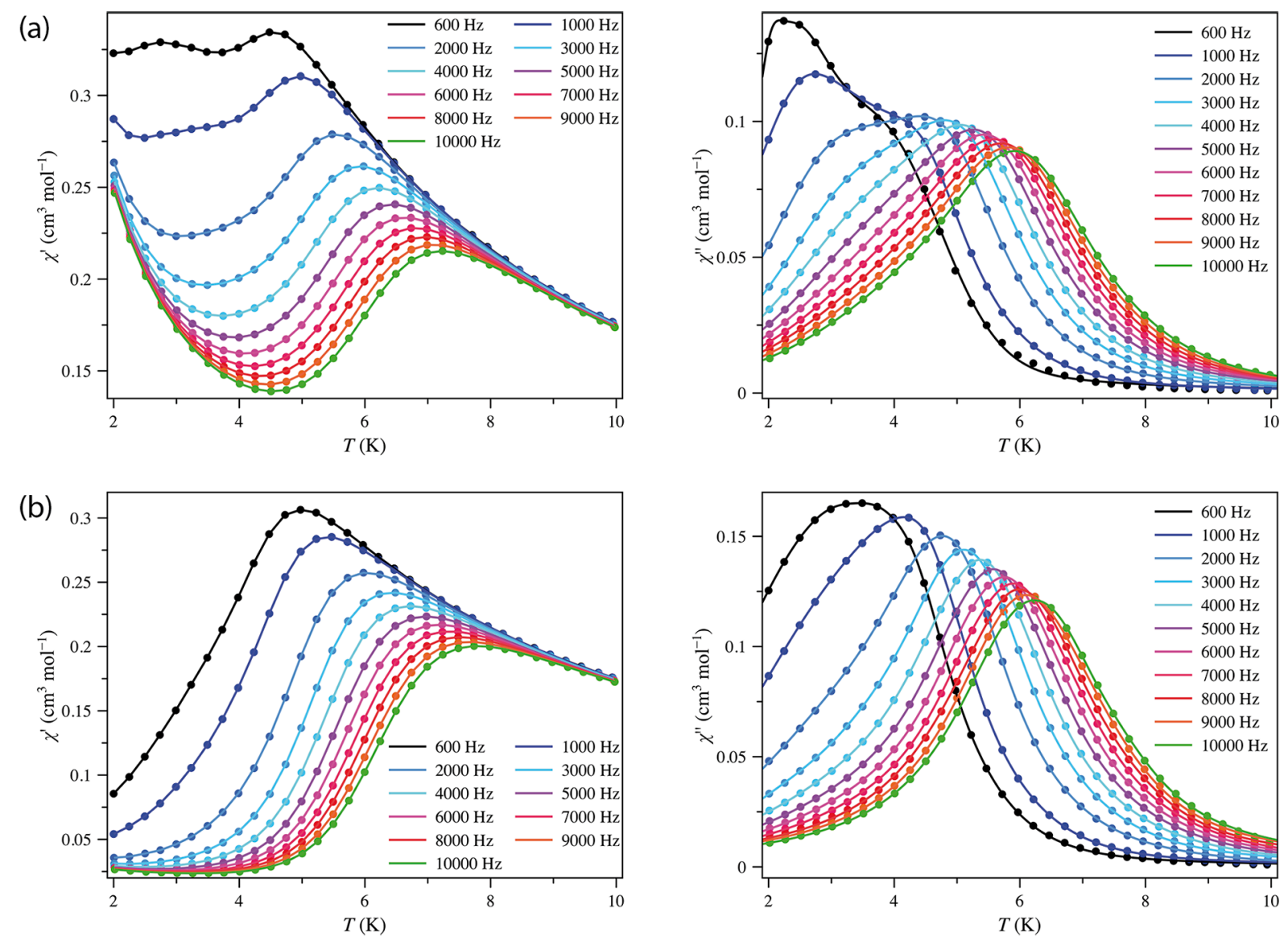

Figure S9. Temperature dependence of $\chi_{M}^{\prime}$ (left) and $\chi^{\prime \prime}$ (right) of 2 in applied dc fields of 0.5 (a) and 2.5 (b) $\mathrm{kG}$ and under $\pm 5.0 \mathrm{G}$ oscillating field at frequencies in the range of 0.6 (black) to 10.0 (green) $\mathrm{kHz}$. The filled circles and solid lines are experimental data and simulated curves, respectively. 

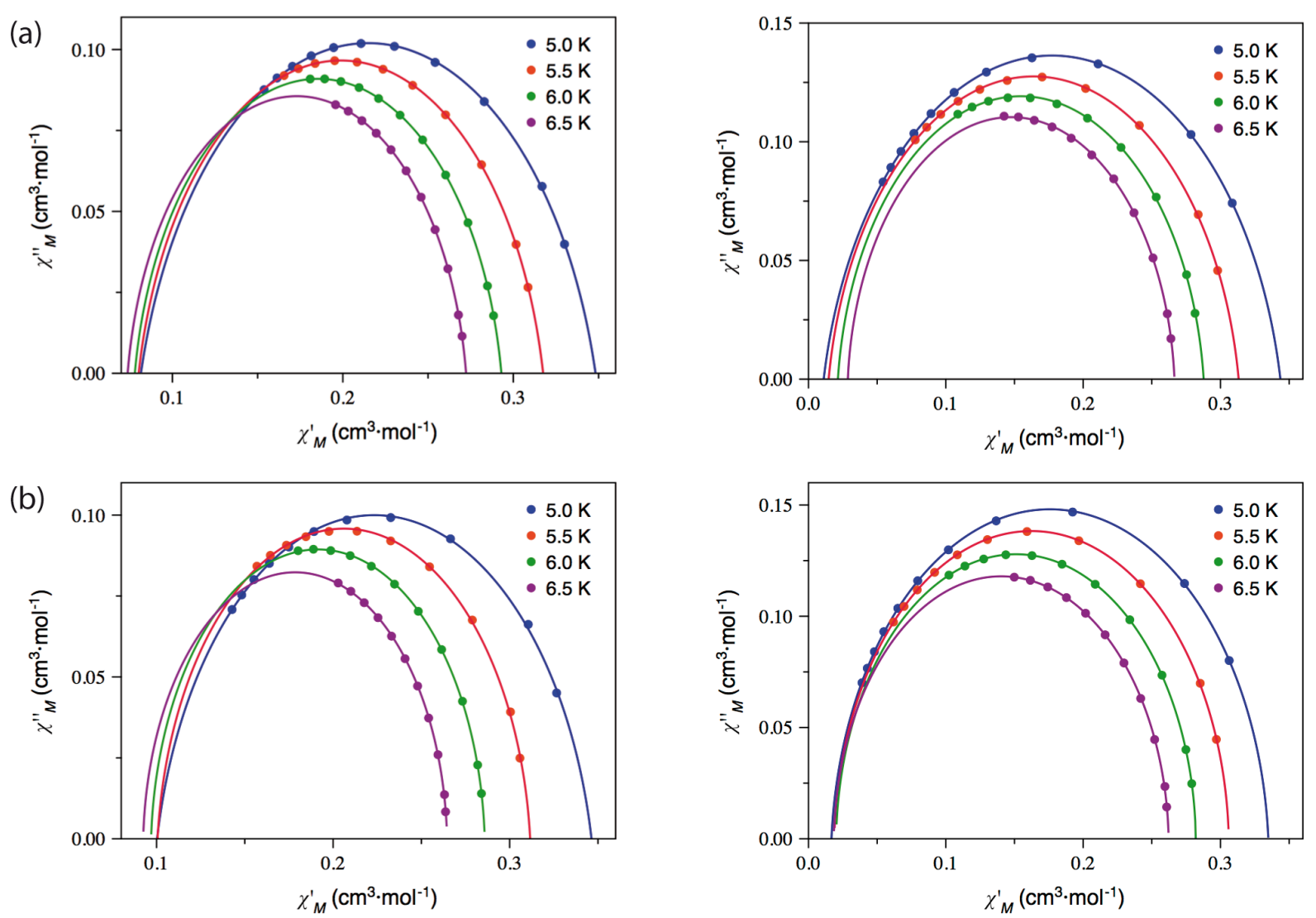

Figure S10. Cole-Cole plots at 5.0 K (blue dots), $5.5 \mathrm{~K}$ (red dots), $6.0 \mathrm{~K}$ (green dots) and 6.5 $\mathrm{K}$ (purple dots) for 1 (a) and 2 (b) under applied dc fields of 0.5 (left) and $2.5 \mathrm{kG}$ (right). Solid lines represent the best fit (see text). 

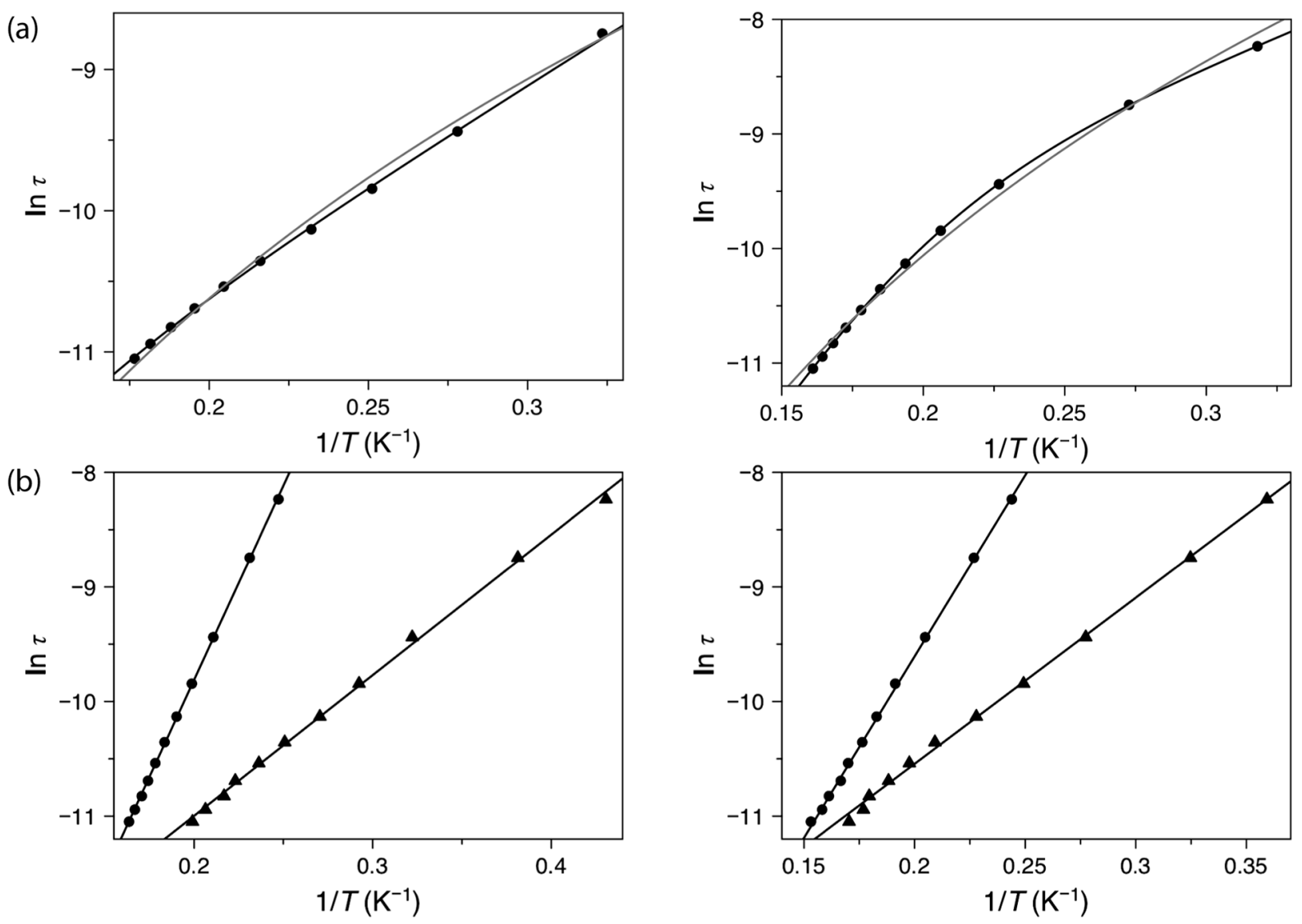

Figure S11. Arrhenius plots for 1 (a) and 2 (b) under applied dc fields of 0.5 (left) and $2.5 \mathrm{kG}$ (right). Solid lines represent the best fit (see text) through the models described in eqs (4) [Orbach + Orbach, in black] and (6) [Raman, in grey]. Error bars do not appear because they are smaller than the dots used to visualize the experimental data (standard deviation in $1 / T$ less than 0.002). 
(a)
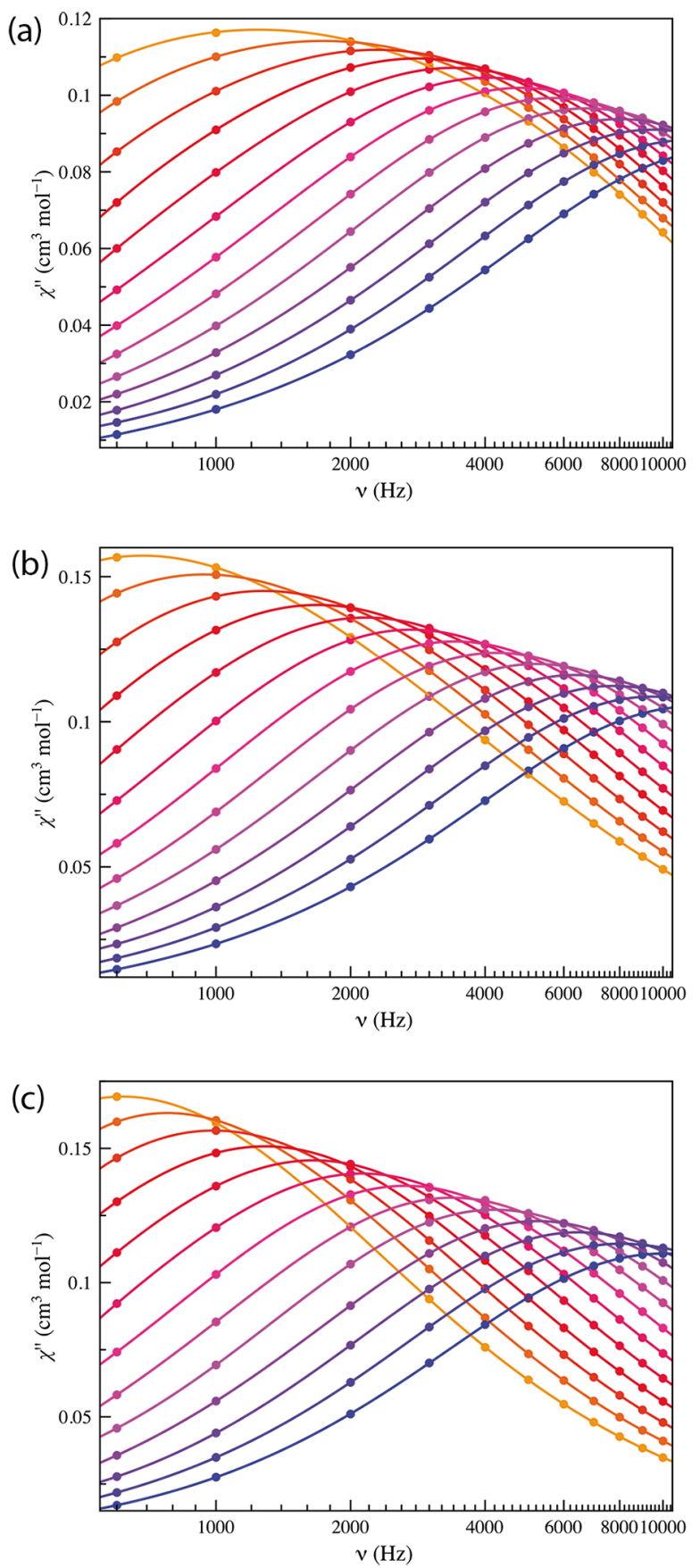
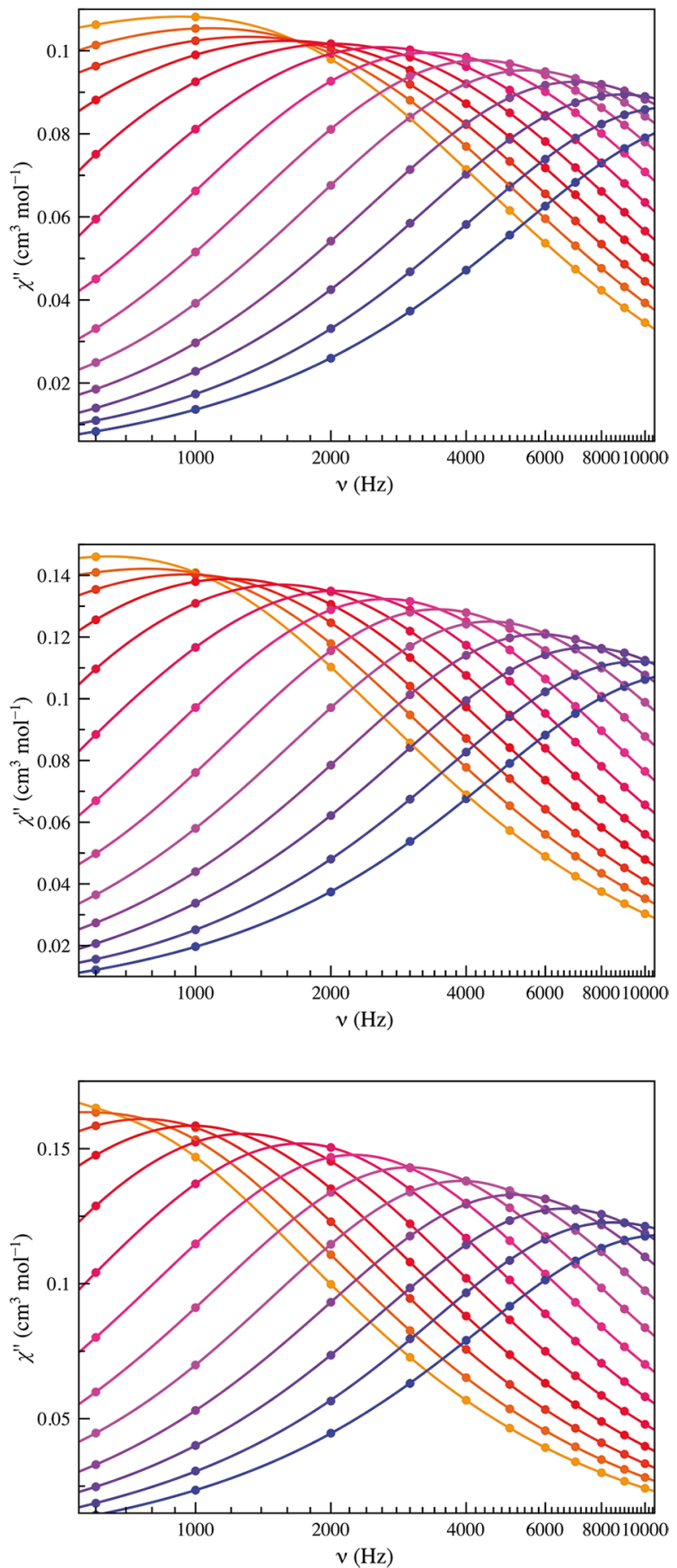

Figure S12. Frequency dependence of $\chi^{\prime \prime} \mathrm{M}$ of 1 (left) and 2 (right) in applied dc fields of 0.5

(a) $1.0 \mathrm{kG}$ (b), and 2.5 (c) $\mathrm{kG}$ and under $\pm 5.0 \mathrm{G}$ oscillating field at temperatures in the range from 3.5 (orange) to $6.5 \mathrm{~K}$ (blue) in steps of $0.25 \mathrm{~K}$. The filled circles and solid lines are experimental data and simulated curves, respectively. 

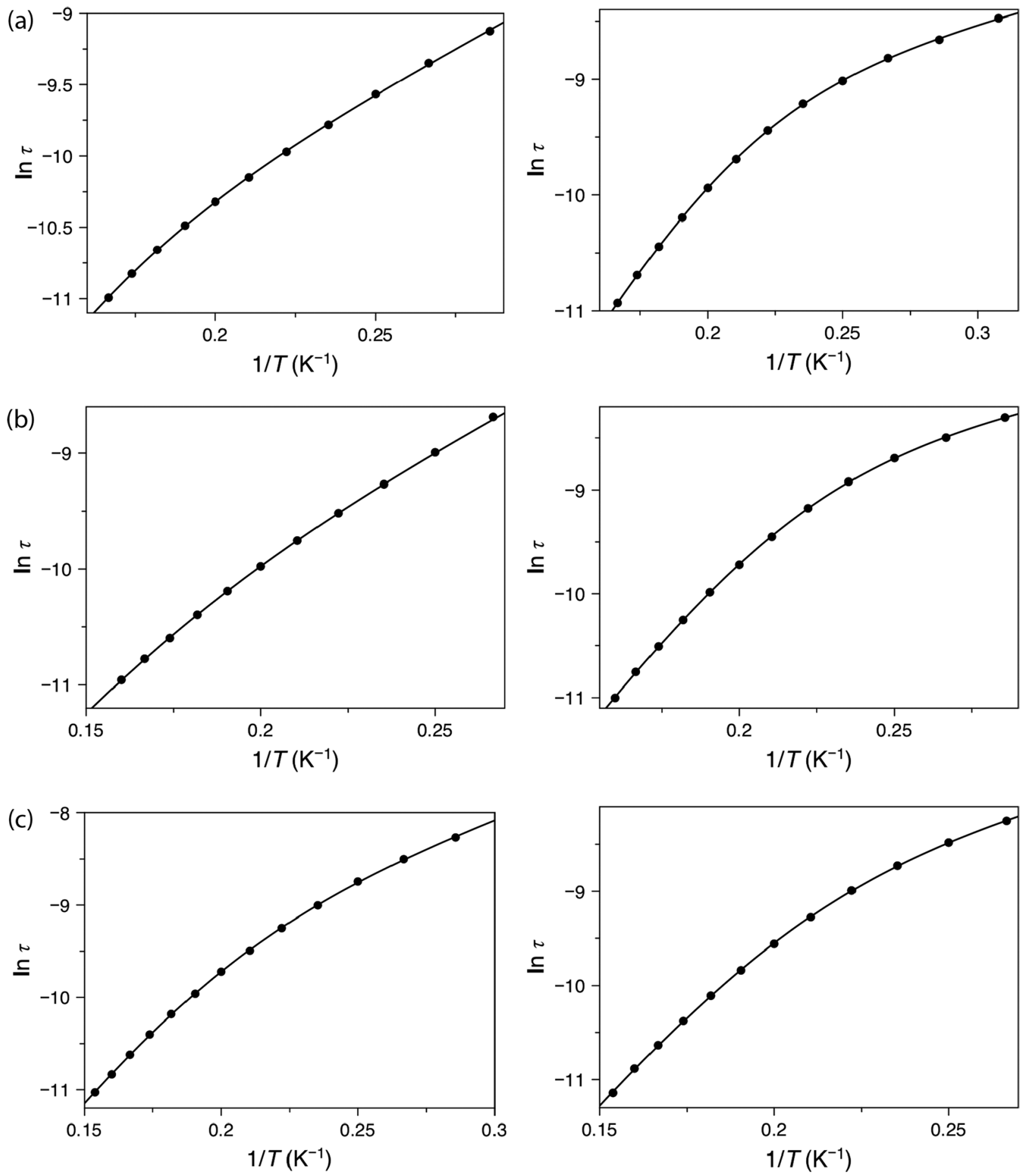

Figure S13. Arrhenius plots for 1 (left) and 2 (right) under applied dc fields of 0.5 (a), 1.0 (b), and $2.5 \mathrm{kG}$ (c). Solid lines represent the best fit (see text) through the model described in eq (4) [Orbach + Orbach, in black]. Error bars do not appear because they are smaller than the dots used to visualize the experimental data (standard deviation in $\ln (\tau)$ less than 0.007 ). 
Table S1. Intermolecular $\pi \cdots \pi$ interactions in $\mathbf{1}$ (distances in $\AA$ and angles in deg).

\begin{tabular}{ccc}
\hline $\mathrm{Cg} \cdots \mathrm{Cg}^{\mathrm{a}}$ & $\mathrm{Cg} \cdots \mathrm{Cg}$ & $\gamma^{\mathrm{p}}$ \\
\hline $\mathrm{Cg} 2 \cdots \mathrm{Cg} 6$ & $3.8215(13)$ & $2.24(10)$ \\
$\mathrm{Cg} 3 \cdots \mathrm{Cg} 14$ & $3.7300(12)$ & $4.58(9)$ \\
$\mathrm{Cg} 3 \cdots \mathrm{Cg} 19$ & $3.9357(13)$ & $3.46(10)$ \\
$\mathrm{Cg} 6 \cdots \mathrm{Cg} 6$ & $3.9836(14)$ & $0.00(10)$ \\
$\mathrm{Cg} 17 \cdots \mathrm{Cg} 20$ & $3.7877(13)$ & $4.76(10)$ \\
\hline
\end{tabular}

${ }^{a} \mathrm{Cg}$ are the six-membered rings: $\mathrm{Cg} 2, \mathrm{~N} 2, \mathrm{C} 21-\mathrm{C} 25 ; \mathrm{Cg} 3, \mathrm{~N} 3, \mathrm{C} 29-\mathrm{C} 31, \mathrm{C} 40 ; \mathrm{Cg} 6, \mathrm{C} 18-\mathrm{C} 21, \mathrm{C} 25$, C26; Cg14, N5, C43-C46, C54; Cg17, N8, C63-C67; Cg19, C46-C49, C53, C54; Cg20, C60-63, C67, C68. ${ }^{b} \gamma$ is the dihedral angle between each pair of mean ring planes 
Table S2. Energy of the calculated quartet $\left(\mathrm{Q}_{\mathrm{i}}\right)$ and triplet $\left(\mathrm{D}_{\mathrm{i}}\right)$ excited states and their contributions to the $D$ and $E$ values for 1 obtained from CASSCF/NEVPT2 calculations. $D_{\mathrm{SS}}$ is the spin-spin contribution to axial $z f s$ parameter, and $D_{\mathrm{Q}}$ and $D_{\mathrm{D}}$ are the sum of spin-orbit contributions coming from quartet and doublet excited states

\begin{tabular}{|c|c|c|c|c|c|c|c|c|c|}
\hline \multicolumn{5}{|c|}{ Col } & \multicolumn{5}{|c|}{$\mathrm{Co} 2$} \\
\hline State & Energy $^{\mathrm{a}}$ & $S$ & $D^{\mathrm{a}}$ & $E^{\mathrm{a}}$ & State & Energy $^{a}$ & $S$ & $D^{\mathrm{a}}$ & $E^{\mathrm{a}}$ \\
\hline$D_{\mathrm{SS}}$ & & 4 & -0.115 & -0.305 & $D_{\mathrm{SS}}$ & & 4 & -0.052 & -0.348 \\
\hline$D_{\mathrm{Q}}$ & & 4 & 46.867 & 12.645 & $D_{\mathrm{Q}}$ & & 4 & 44.176 & 12.289 \\
\hline$D_{\mathrm{D}}$ & & 2 & 1.736 & -1.040 & $D_{\mathrm{D}}$ & & 2 & 2.468 & -1.519 \\
\hline $\mathrm{Q}_{1}$ & 978.6 & 4 & 31.625 & 31.852 & $\mathrm{Q}_{1}$ & 1026.4 & 4 & 29.817 & 30.490 \\
\hline $\mathrm{Q}_{2}$ & 1686.1 & 4 & 17.498 & -17.199 & $\mathrm{Q}_{2}$ & 1791.1 & 4 & 15.661 & -15.350 \\
\hline $\mathrm{Q}_{3}$ & 8424.8 & 4 & 4.337 & -3.140 & $\mathrm{Q}_{3}$ & 8108.1 & 4 & 2.128 & -3.242 \\
\hline $\mathrm{Q}_{4}$ & 8899.5 & 4 & -7.024 & 0.423 & $\mathrm{Q}_{4}$ & 8757.8 & 4 & -3.879 & -0.039 \\
\hline $\mathrm{Q}_{5}$ & 10346.9 & 4 & 0.240 & 0.744 & $\mathrm{Q}_{5}$ & 10727.7 & 4 & 0.233 & 0.476 \\
\hline $\mathrm{Q}_{6}$ & 18408.0 & 4 & 0.022 & -0.021 & $\mathrm{Q}_{6}$ & 18352.7 & 4 & 0.032 & -0.026 \\
\hline $\mathrm{Q}_{7}$ & 22268.9 & 4 & 0.078 & -0.061 & $\mathrm{Q}_{7}$ & 22202.0 & 4 & 0.070 & -0.067 \\
\hline $\mathrm{Q}_{8}$ & 22648.1 & 4 & 0.065 & 0.058 & $\mathrm{Q}_{8}$ & 22649.6 & 4 & 0.070 & 0.069 \\
\hline $\mathrm{Q}_{9}$ & 24175.4 & 4 & 0.026 & -0.011 & $\mathrm{Q}_{9}$ & 24254.5 & 4 & 0.044 & -0.022 \\
\hline $\mathrm{D}_{1}$ & 11145.2 & 2 & -0.951 & 0.945 & $\mathrm{D}_{1}$ & 10947.2 & 2 & -0.358 & 0.724 \\
\hline $\mathrm{D}_{2}$ & 12536.1 & 2 & 2.408 & -1.529 & $\mathrm{D}_{2}$ & 12927.2 & 2 & 2.326 & -1.698 \\
\hline $\mathrm{D}_{3}$ & 18472.9 & 2 & -0.041 & -0.032 & $\mathrm{D}_{3}$ & 17935.1 & 2 & -0.041 & -0.040 \\
\hline $\mathrm{D}_{4}$ & 19444.2 & 2 & -0.018 & 0.020 & $\mathrm{D}_{4}$ & 19490.8 & 2 & -0.020 & 0.018 \\
\hline $\mathrm{D}_{5}$ & 20008.4 & 2 & -1.230 & -1.246 & $\mathrm{D}_{5}$ & 19972.9 & 2 & -1.175 & -1.179 \\
\hline $\mathrm{D}_{6}$ & 20162.1 & 2 & -0.518 & 0.434 & $\mathrm{D}_{6}$ & 20261.3 & 2 & -0.738 & 0.498 \\
\hline
\end{tabular}




\begin{tabular}{|c|c|c|c|c|c|c|c|c|c|}
\hline $\mathrm{D}_{7}$ & 20669.9 & 2 & -0.948 & 0.865 & $\mathrm{D}_{7}$ & 20814.0 & 2 & -0.827 & 0.729 \\
\hline $\mathrm{D}_{8}$ & 20769.5 & 2 & -0.135 & -0.142 & $\mathrm{D}_{8}$ & 21010.5 & 2 & -0.117 & -0.146 \\
\hline $\mathrm{D}_{9}$ & 22975.8 & 2 & 3.887 & -0.003 & $\mathrm{D}_{9}$ & 22974.3 & 2 & 4.085 & -0.009 \\
\hline $\mathrm{D}_{10}$ & 23374.5 & 2 & -0.047 & 0.003 & $\mathrm{D}_{10}$ & 23415.3 & 2 & -0.020 & 0.012 \\
\hline $\mathrm{D}_{11}$ & 23523.2 & 2 & -0.062 & -0.049 & $\mathrm{D}_{11}$ & 23498.9 & 2 & -0.025 & -0.022 \\
\hline $\mathrm{D}_{12}$ & 26238.5 & 2 & -0.059 & 0.061 & $\mathrm{D}_{12}$ & 26054.6 & 2 & -0.055 & 0.036 \\
\hline $\mathrm{D}_{13}$ & 29055.3 & 2 & -0.151 & 0.072 & $\mathrm{D}_{13}$ & 28995.2 & 2 & -0.354 & 0.336 \\
\hline $\mathrm{D}_{14}$ & 29056.6 & 2 & -0.247 & -0.126 & $\mathrm{D}_{14}$ & 29096.2 & 2 & -0.202 & -0.395 \\
\hline $\mathrm{D}_{15}$ & 30753.6 & 2 & -0.072 & -0.077 & $\mathrm{D}_{15}$ & 30582.1 & 2 & 0.002 & -0.036 \\
\hline $\mathrm{D}_{16}$ & 30787.5 & 2 & -0.011 & 0.022 & $\mathrm{D}_{16}$ & 30847.9 & 2 & -0.005 & 0.001 \\
\hline $\mathrm{D}_{17}$ & 30903.7 & 2 & -0.044 & -0.031 & $\mathrm{D}_{17}$ & 30891.2 & 2 & -0.021 & -0.021 \\
\hline $\mathrm{D}_{18}$ & 31968.4 & 2 & -0.004 & 0.001 & $\mathrm{D}_{18}$ & 32146.7 & 2 & -0.004 & 0.003 \\
\hline $\mathrm{D}_{19}$ & 32508.6 & 2 & 0.141 & -0.383 & $\mathrm{D}_{19}$ & 32591.1 & 2 & 0.178 & -0.478 \\
\hline $\mathrm{D}_{20}$ & 33550.3 & 2 & -0.162 & 0.155 & $\mathrm{D}_{20}$ & 33657.9 & 2 & -0.161 & 0.148 \\
\hline
\end{tabular}

${ }^{\mathrm{a}}$ Values in $\mathrm{cm}^{-1}$. 
Table S3. Energy of the calculated quartet $\left(\mathrm{Q}_{\mathrm{i}}\right)$ and triplet $\left(\mathrm{D}_{\mathrm{i}}\right)$ excited states and their contributions to the $D$ and $E$ values for 2 obtained from CASSCF/NEVPT2 calculations. $D_{\mathrm{SS}}$ is the spin-spin contribution to axial $z f s$ parameter, and $D_{\mathrm{Q}}$ and $D_{\mathrm{T}}$ are the sum of spin-orbit contributions coming from quartet and doublet excited states

\begin{tabular}{|c|c|c|c|c|c|c|c|c|c|}
\hline \multicolumn{5}{|c|}{ Compound 2} & \multicolumn{5}{|c|}{ Compound 2} \\
\hline State & Energy $^{a}$ & $S$ & $D^{\mathrm{a}}$ & $E^{\mathrm{a}}$ & State & Energy $^{\mathrm{a}}$ & $S$ & $D^{\mathrm{a}}$ & $E^{\mathrm{a}}$ \\
\hline$D_{\mathrm{SS}}$ & & 4 & 0.456 & -0.137 & $\mathrm{D}_{5}$ & 20033.8 & 2 & -1.282 & -1.270 \\
\hline$D_{\mathrm{Q}}$ & & 4 & 51.205 & 4.361 & $\mathrm{D}_{6}$ & 20050.3 & 2 & -0.615 & 0.564 \\
\hline$D_{\mathrm{D}}$ & & 2 & 1.469 & -1.432 & $\mathrm{D}_{7}$ & 20198.5 & 2 & -0.755 & 0.756 \\
\hline $\mathrm{Q}_{1}$ & 1018.4 & 4 & 30.016 & 30.555 & $\mathrm{D}_{8}$ & 20307.3 & 2 & -0.146 & -0.112 \\
\hline $\mathrm{Q}_{2}$ & 1300.8 & 4 & 24.123 & -24.101 & $\mathrm{D}_{9}$ & 22709.1 & 2 & 3.748 & -0.000 \\
\hline $\mathrm{Q}_{3}$ & 8741.9 & 4 & 4.280 & -4.378 & $\mathrm{D}_{10}$ & 23202.6 & 2 & -0.044 & 0.041 \\
\hline $\mathrm{Q}_{4}$ & 9079.2 & 4 & -7.281 & 1.249 & $\mathrm{D}_{11}$ & 23205.1 & 2 & -0.085 & -0.073 \\
\hline $\mathrm{Q}_{5}$ & 9983.0 & 4 & -0.114 & 1.059 & $\mathrm{D}_{12}$ & 26328.7 & 2 & -0.090 & 0.085 \\
\hline $\mathrm{Q}_{6}$ & 18491.4 & 4 & 0.013 & -0.012 & $\mathrm{D}_{13}$ & 28560.1 & 2 & 0.097 & -0.266 \\
\hline $\mathrm{Q}_{7}$ & 22234.8 & 4 & 0.078 & 0.077 & $\mathrm{D}_{14}$ & 29533.4 & 2 & -0.281 & 0.266 \\
\hline $\mathrm{Q}_{8}$ & 22435.7 & 4 & 0.082 & -0.081 & $\mathrm{D}_{15}$ & 30561.8 & 2 & -0.075 & -0.075 \\
\hline $\mathrm{Q}_{9}$ & 24323.3 & 4 & 0.008 & -0.007 & $\mathrm{D}_{16}$ & 30849.6 & 2 & -0.040 & 0.041 \\
\hline $\mathrm{D}_{1}$ & 11231.9 & 2 & -0.924 & 0.932 & $\mathrm{D}_{17}$ & 30971.7 & 2 & -0.084 & -0.085 \\
\hline $\mathrm{D}_{2}$ & 11747.9 & 2 & 2.186 & -1.949 & $\mathrm{D}_{18}$ & 31711.8 & 2 & -0.001 & 0.001 \\
\hline $\mathrm{D}_{3}$ & 18911.3 & 2 & -0.050 & 0.051 & $\mathrm{D}_{19}$ & 32435.1 & 2 & 0.161 & -0.529 \\
\hline $\mathrm{D}_{4}$ & 19288.6 & 2 & -0.019 & -0.026 & $\mathrm{D}_{20}$ & 33393.7 & 2 & -0.232 & 0.216 \\
\hline
\end{tabular}

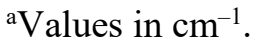


Table S4. Selected ac magnetic data for $\mathbf{1}$ and $\mathbf{2}$ at different dc applied fields

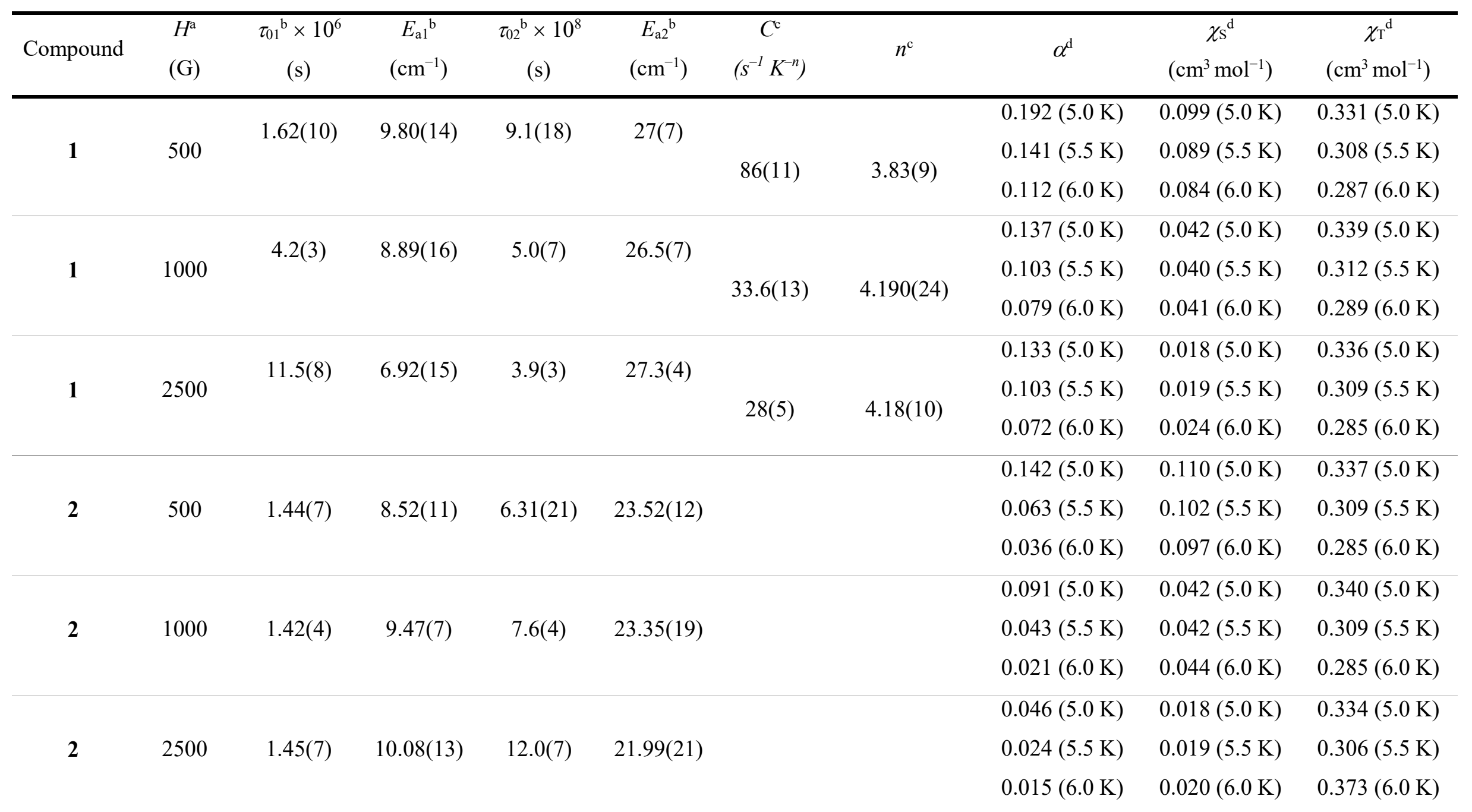

${ }^{\mathrm{a}}$ Applied dc magnetic field. ${ }^{\mathrm{b}}$ The values of the pre-exponential factor $\left(\tau_{0}\right)$ and activation energy $\left(E_{\mathrm{a}}\right)$ are calculated through the Arrhenius law $\left[\tau^{-1}=\tau_{0}{ }^{-1} \exp (-\right.$ $\left.\left.E_{\mathrm{a}} / k_{\mathrm{B}} T\right)\right]{ }^{\mathrm{c}}$ The preexponential and exponential coefficients for the Raman mechanism $\left[\tau^{-l}=C T^{n}\right]$. ${ }^{\mathrm{d}}$ The values of the $\alpha$ parameter, adiabatic $(\chi \mathrm{s})$ and isothermal $\left(\chi_{\mathrm{T}}\right)$ susceptibilities are calculated from the experimental data at different temperatures through the generalized Debye law (see text). 
Table S5. Selected results obtained from the analysis of the ac magnetic data for $\mathbf{1}$ at different dc applied fields using different combinations of the relaxation mechanisms

\begin{tabular}{|c|c|c|c|c|c|c|c|c|}
\hline Equation $^{\mathrm{a}}$ & $H^{\mathrm{b}}(\mathrm{G})$ & $\bar{\tau} 01^{\mathrm{c}} \times 10^{6}(\mathrm{~s})$ & $E_{\mathrm{a} 1}{ }^{\mathrm{c}}\left(\mathrm{cm}^{-1}\right)$ & $\tau_{02}{ }^{\mathrm{c}} \times 10^{8}(\mathrm{~s})$ & $E_{\mathrm{a} 2}{ }^{\mathrm{c}}\left(\mathrm{cm}^{-1}\right)$ & $C^{\mathrm{d}}\left(s^{-1} K^{-n}\right)$ & $n^{\mathrm{d}}$ & $A^{\mathrm{e}}$ \\
\hline (4) & & & & $91(6)$ & $11.6(3))$ & & & $420(80)$ \\
\hline (5) & & $1.62(10)$ & $9.80(14)$ & $9.1(18)$ & $27(7)$ & & & \\
\hline (6) & 500 & & & & & $410(80)$ & $2.98(11)$ & $-1700(300)$ \\
\hline (7) & & & & & & $86(11)$ & $3.83(9)$ & \\
\hline (8) & & & & $123(4)$ & $10.43(7)$ & $2(18) \times 10^{-11}$ & $19(5)$ & \\
\hline (4) & & & & $31(4)$ & $17.0(5)$ & & & $900(70)$ \\
\hline (5) & & $4.2(3)$ & $8.89(16)$ & $5.0(7)$ & $26.5(7)$ & & & \\
\hline (6) & 1000 & & & & & $22.4(20)$ & $4.41(5)$ & $210(40)$ \\
\hline (7) & & & & & & $33.6(13)$ & $4.190(24)$ & \\
\hline (8) & & & & $0.12(6)$ & $50.4(22)$ & $38.7(3)$ & $4.082(6)$ & \\
\hline (4) & & & & $14.9(25)$ & $20.8(7)$ & & & $1090(50)$ \\
\hline (5) & & $11.5(8)$ & $6.92(15)$ & $3.9(3)$ & 27.3(4) & & & \\
\hline (6) & 2500 & & & & & $3.4(4)$ & $5.33(6)$ & $730(30)$ \\
\hline (7) & & & & & & $28(5)$ & $4.18(10)$ & \\
\hline (8) & & & & $1150(80)$ & $6.92(15)$ & $99.5(23)$ & $3.166(20)$ & \\
\hline
\end{tabular}

${ }^{a}$ Equations used in the analysis of the experimental data which described in the main text. ${ }^{b}$ Applied dc magnetic field. ${ }^{c}$ The values of the pre-exponential factor $\left(\tau_{0}\right)$ and activation energy $\left(E_{\mathrm{a}}\right)$ are calculated through the Arrhenius law $\left[\tau^{-1}=\tau_{0}^{-1} \exp \left(-E_{\mathrm{a}} / k_{\mathrm{B}} T\right)\right]{ }^{\mathrm{d}}$ The preexponential and exponential coefficients for the Raman mechanism $\left[\tau^{-1}=C T^{n}\right]$. ${ }^{\mathrm{e}}$ The values of the $A$ coefficient for the direct mechanism $\left[\tau^{-1}=A T\right]$. 
Table S6. A comparison between a selection of theoretical and experimental vibrational frequencies for $\mathbf{1}$ and $\mathbf{2}$

\begin{tabular}{|c|c|c|c|c|c|c|}
\hline & \multicolumn{3}{|c|}{1} & \multicolumn{3}{|c|}{2} \\
\hline & $v_{\exp }^{\mathrm{a}}$ & $v_{\text {theo }}{ }^{\mathrm{a}}$ & $\sigma^{b}$ & $v_{\exp }{ }^{a}$ & $V_{\text {theo }}{ }^{a}$ & $\sigma^{b}$ \\
\hline \multirow[t]{7}{*}{ IR Spectr. } & 1594 & 1582.9 & 0.69 & 1600 & 1582.0 & 1.13 \\
\hline & 1420 & 1415.3 & 0.33 & 1427 & 1432.8 & 0.41 \\
\hline & 1090 & 1072.2 & 1.63 & 1086 & 1077.8 & 0.76 \\
\hline & 937 & 933.1 & 0.42 & 929 & 933.4 & 0.47 \\
\hline & 732 & 745.9 & 1.90 & 794 & 817.4 & 2.95 \\
\hline & 683 & 679.2 & 0.56 & 721 & 713.3 & 1.07 \\
\hline & 622 & 619.8 & 0.35 & 623 & 633.2 & 1.64 \\
\hline \multirow[t]{9}{*}{ FIRMS Spectr. } & 164 & 163.8 & 0.12 & 159 & 162.7 & 2.33 \\
\hline & 143 & 145.0 & 1.40 & 153 & 150.5 & 1.63 \\
\hline & 138 & 138.3 & 0.22 & 142 & 145.9 & 2.75 \\
\hline & 131 & 132.2 & 0.92 & 137 & 134.0 & 2.19 \\
\hline & 102 & 101.3 & 0.69 & 102 & 99.3 & 2.65 \\
\hline & 97 & 95.8 & 1.24 & 92 & 94.3 & 2.50 \\
\hline & 93 & 95.8 & 3.01 & & & \\
\hline & 89 & 90.9 & 2.13 & & & \\
\hline & 82 & 82.5 & 0.61 & & & \\
\hline
\end{tabular}

${ }^{a}$ Experimental values were extracted from IR and FIRMS spectra in $\mathrm{cm}^{-1}$. ${ }^{\mathrm{b}}$ The $\sigma$ parameter, defined as $100 \times\left|v_{\text {exp }}-v_{\text {theo }}\right| / v_{\text {exp }}$, provides an estimation in percentage of the shift of the theoretical values from the experimental ones 
Table S7. Selected ac magnetic data for $\mathbf{1}$ and $\mathbf{2}$ at different dc applied fields extracted from the frequency dependence of $\chi$ "M

\begin{tabular}{cccccc}
\hline Compound & $H^{\mathrm{a}}(\mathrm{G})$ & $\tau_{01}^{\mathrm{b}} \times 10^{6}(\mathrm{~s})$ & $E_{\mathrm{a} 1}^{\mathrm{b}}\left(\mathrm{cm}^{-1}\right)$ & $\tau_{02}^{\mathrm{b}} \times 10^{8}(\mathrm{~s})$ & $E_{\mathrm{a} 2}^{\mathrm{b}}\left(\mathrm{cm}^{-1}\right)$ \\
\hline $\mathbf{1}$ & 500 & $3.6(5)$ & $8.3(3)$ & $3.5(20)$ & $30(3)$ \\
$\mathbf{1}$ & 1000 & $2.68(11)$ & $10.88(10)$ & $5.1(3)$ & $28.6(4)$ \\
$\mathbf{1}$ & 2500 & $13(3)$ & $7.4(5)$ & $5.4(9)$ & $27.0(8)$ \\
\hline $\mathbf{2}$ & 500 & $33(3)$ & $4.22(19)$ & $2.75(25)$ & $27.9(4)$ \\
$\mathbf{2}$ & 1000 & $49(7)$ & $4.1(3)$ & $3.2(3)$ & $27.9(4)$ \\
$\mathbf{2}$ & 2500 & $23(6)$ & $6.6(6)$ & $2.0(3)$ & $30.6(7)$ \\
\hline
\end{tabular}

${ }^{a}$ Applied dc magnetic field. ${ }^{\mathrm{b}}$ The values of the pre-exponential factor $\left(\tau_{0}\right)$ and activation energy $\left(E_{\mathrm{a}}\right)$ are calculated through the Arrhenius law $\left[\tau^{-1}=\tau_{0}^{-1} \exp (-\right.$ $\left.\left.E_{\mathrm{a}} / k_{\mathrm{B}} T\right)\right]^{\mathrm{c}}$ 